\title{
The influence of nonpharmacological complex therapy conducted at community day-care center on the cognitive functions and mood in older adults
}

\author{
Agnieszka Gorzkowska1, Izabela Zacharska-Quaium2, Joanna Cholewa3, Jarosław Cholewa4* \\ 1 Department of Neurorehabilitation, Faculty of Medical Sciences in Katowice, Medical University of Silesia, \\ Katowice, Poland, agorzkowska@sum.edu.pl \\ 2 Community Day-Care Center by Chance for Health Association in Golub-Dobrzyn, District Hospital, Golub- \\ Dobrzyn, Poland, izaq@op.pl \\ 3 Institute of Physioterapy and Health Sciences, The Jerzy Kukuczka Academy of Physical Education, Katowice, \\ Poland, a.cholewa@awf.katowice.pl \\ 4 Department of Health Related Physical Activity and Tourism, The Jerzy Kukuczka Academy of Physical \\ Education in Katowice, Katowice, Poland; j.cholewa@awf.katowice.pl \\ * corresponding author: j.cholewa@awf.katowice.pl, phone number: +48 6015600 11. The Jerzy Kukuczka \\ Academy of Physical Education in Katowice, 40-065 Katowice ul. Mikołowska 72A, Poland
}

\begin{abstract}
Nonpharmacological interventions in elderly may lead to the reduction of cognitive and depressive symptoms. The aim of the study was to evaluate changes in cognitive functions and mood in older adults participating in therapy, conducted in the community day-care center (CD-CC). The study group (SG) included 46 elderly adults (21 M, $25 \mathrm{~W}$ ), the control group (CG) - 45 adults (12 M, $33 \mathrm{~W}$ ), who participated in the activities of the University of the Third Age (U3A). The following measuring tools were used: Mini-Mental State Examination (MMSE), Clock-Drawing Test (CDT), Verbal Fluency Test (VFT), Digit Span Test (DST), Stroop Color and Word Test (SCWT), Beck's Depression Inventory (BDI), and Hospital Anxiety and Depression Scale (HADS). The intervention consisted of CD-CC 6-month nonpharmacological therapy. In the SG, compared to the CG, the scores on the: MMSE, CDT, VFT, DST, and SCWT were significantly lower $(\mathrm{p}<0,05)$, BDI was significantly higher $(p<0,05)$. After intervention, the $S G$ and the $C G$, did not show substantial differences in their scores on the: MMSE, CDT, and BDI. In the SG, a significant improvement $(p<0,05)$ was reported on the: VFT, BDI, and HADS scores. The CD-CC complex therapy can be helpful for the cognitive and emotional elderly functioning.
\end{abstract}

Keywords: cognition, depression, aging, elderly, nonpharmacological therapy, community daycare center

\section{Introduction}

Optimization of the care for older adults, with mental disorders, and in particular with chronically disturbed mental functioning of organic origin, related to comorbidities associated with aging process, represents an enormous challenge for all of the healthcare systems in the developed countries, worldwide [1,2].

The fact that the elderly age consists of an increasingly prolonged stage of the human life, causes the occurrence of biological processes naturally associated with advanced age, became a growing challenge that inspires a great interest among researchers, partially because, the results of many 
studies on aging can determine, to some degree, current political and socio-economical decisions on a national scale.

The most common mental disorders that occur in our society include depression and mood disorders, such as sadness, anxiety and fear [3]. Prevalence of depressive disorders in elderly persons is estimated at approximately $4 \%-6 \%$ of the population, and among patients of the primary care physicians, it is even higher (about 9\% - 15\%) [4]. Cognitive decline is also considered one of the most frightening aspects of aging [5]. The prevalence of cognitive impairment increases with age.

Community day-care centers (CD-CCs) (also known as self-help CD-CCs) are social service institutions that have functioned in Poland since 1995.

CD-CCs type $\mathrm{C}$ are designated for individuals with so called other chronic disturbances of mental functions, including elderly persons, who suffer from chronic mental disorders due to underlying organic causes, relevant to comorbidities associated with advancing age.

A CD-CC facility provides services at least 5 days a week, for 8 hours daily, including at least 6 hours of therapy per day. In many countries, similar forms of systematic therapeutic programs, including mostly occupational therapy for elderly persons have been designed and implemented (e. g., in Sweden or the USA). The low-intensity psychological interventions (self-help, psychoeducation, bibliotherapy, internet cognitive-behavioral therapy: $\mathrm{iCBT}$ ) for older adults with mild-to-moderate mental health problems can be effective [6]. Attempts at quality improvement in community mental health services for older people are stymied by a lack of robust measures [7].

CD-CC represents a place, in which a nonpharmacological therapy for groups of elderly persons has been conducted. For this reason, it appears to be one of the best structures that can create favorable conditions for social integration and general activation of older persons in their local community (while staying in their own homes does not cause the discomfort of institutionalization) [8]. For this reason, CD-CC could be a desirable environment for research purposes.

\section{The aim of the study}

The aim of this study was to evaluate the influence of nonpharmacological complex therapy conducted for 6 months in the CD-CC on changes in cognitive functions and moodamong the elderly participants.

\section{Material and method}

91 persons were enrolled into the study. The study was granted an approval of the Bioethical Commission of the University of Nicolaus Copernicus in Torun, Poland, at the Collegium Medicum of Ludwik Rydygier, in Bydgoszcz, Poland, (number of the approval KB 452/2016). Written informed consent was signed by all of the participants.

The study group (SG) included 46 elderly adults $21 \mathrm{Men}(\mathrm{M})$ and 25 Women (W) with mental disorders, due to organic origin, related to morbidities associated with aging, who attended CD-CC. The inclusion criteria to the SG were as follows: 1 . A recommendation for obtaining services at the $\mathrm{CD}-\mathrm{CC}$ type $\mathrm{C}$, meaning "the other chronic mental disorders, including among others, chronic disturbances of mental functioning of organic origin, related to comorbidities associated with aging, 2 . An ability to understand the study goal and to perform psychological tests, 3 . Age $\geq 55$ years, 4 . A signed informed consent form.

The main exclusion criteria were serious somatic and mental diseases (other than in the point 1 of the inclusion criteria), which may have a substantial influence on cognitive and physical level of functioning.

The control group (CG) included 45 adults, aged $\geq 55$ years ( $12 \mathrm{M}$ and $33 \mathrm{~W}$ ), who participated in the activities of the University of the Third Age (U3A). The inclusion criteria to the CG were as follows: 
1.absence of serious somatic and mental diseases, 2. An ability to understand the study goal and to perform neuropsychological tests, 3 . Age $\geq 55$ years, 4 . A signed informed consent form.

The following methodological tools of appraisal were used in this study: Survey of demographic data, Mini-Mental State Examination (MMSE), Clock-Drawing Test (CDT), Verbal Fluency Test (VFT), Digit Span Test (DST), Stroop Color and Word Test (SCWT), Beck's Depression Inventory (BDI), and Hospital Anxiety and Depression Scale (HADS).

A study intervention in the SG consisted of 6-month nonpharmacological actions (complex therapy) conducted at the CD-CC (Table 1). 
Table 1. Weekly task plan and schedule of the therapy conducted at the CD-CC

\begin{tabular}{|c|c|c|c|c|}
\hline Monday & Tuesday & Wednesday & Thursday & Friday \\
\hline $\begin{array}{c}\text { 7:30-9:00 } \\
\text { personals rehabilitation } \\
\text { with a physiotherapist, } \\
\text { conversations, press at } \\
\text { shared tea / coffee }\end{array}$ & $\begin{array}{c}\text { 7:30-9:00 } \\
\text { personals rehabilitation } \\
\text { with a physiotherapist, } \\
\text { conversations, press at } \\
\text { shared tea / coffee }\end{array}$ & $\begin{array}{c}\text { 7:30-9:00 } \\
\text { personals rehabilitation } \\
\text { with a physiotherapist, } \\
\text { conversations, press at } \\
\text { shared tea / coffee }\end{array}$ & $\begin{array}{c}\text { 7:30-9:00 } \\
\text { personals rehabilitation } \\
\text { with a physiotherapist, } \\
\text { conversations, press at } \\
\text { shared tea / coffee }\end{array}$ & $\begin{array}{c}\text { 7:30-9:00 } \\
\text { personals rehabilitation } \\
\text { with a physiotherapist, } \\
\text { conversations, press at } \\
\text { shared tea / coffee }\end{array}$ \\
\hline 9:00-9:30 & $9: 00-9: 30$ & 9:00-9:30 & 9:00-9:30 & $9: 00-9: 30$ \\
\hline $\begin{array}{l}\text { Movement therapy } \\
\text { Shared morning gymnastics }\end{array}$ & $\begin{array}{l}\text { Movement therapy } \\
\text { Shared morning gymnastics }\end{array}$ & $\begin{array}{l}\text { Movement therapy } \\
\text { Shared morning gymnastics } \\
\text { / dance }\end{array}$ & $\begin{array}{l}\text { Movement therapy } \\
\text { Shared morning gymnastics }\end{array}$ & $\begin{array}{l}\text { Movement therapy } \\
\text { Shared morning gymnastics }\end{array}$ \\
\hline 9:30-10:00 & 9:30-10:00 & 9:30-10:00 & 9:30-10:00 & 9:30-10:00 \\
\hline Breakfast & Breakfast & Breakfast & Breakfast & Breakfast \\
\hline $10: 00-11: 30$ & $10: 00-11 ; 30$ & $10: 00-11: 30$ & 10:00-11:30 & 10:00-11:30 \\
\hline $\begin{array}{l}\text { occupational therapy in } \\
\text { selected small groups, } \\
\text { culinary training, } \\
\text { budget training, leisure } \\
\text { skills }\end{array}$ & $\begin{array}{l}\text { occupational therapy in } \\
\text { selected small groups, } \\
\text { rhythm classes, } \\
\text { choreotherapy, music } \\
\text { group }\end{array}$ & $\begin{array}{l}\text { occupational therapy in } \\
\text { selected small groups } \\
\text { relaxation training, } \\
\text { breathing exercises }\end{array}$ & $\begin{array}{l}\text { occupational therapy in } \\
\text { selected small groups } \\
\text { table games, fun, } \\
\text { sports, } \\
\text { laughter therapy }\end{array}$ & $\begin{array}{l}\text { occupational therapy in } \\
\text { selected small groups } \\
\text { manual art and technical } \\
\text { classes, handicrafts }\end{array}$ \\
\hline $11: 30-12: 00$ & $11: 30-12: 00$ & 11:30-12:00 & $11: 30-12: 00$ & 11:30-12:00 \\
\hline Coffee & Coffee & Coffee & Coffee & Coffee \\
\hline $\begin{array}{c}\text { 12:00-13:00 } \\
\text { group classes / theatre } \\
\text { group / karaoke }\end{array}$ & $\begin{array}{c}\text { 12:00-13:00 } \\
\text { walk in groups }\end{array}$ & $\begin{array}{c}12: 00-13: 00 \\
\text { group dlasses, Nordic } \\
\text { Walking } \\
\end{array}$ & $\begin{array}{c}\text { 12:00-13:00 } \\
\text { walk in groups }\end{array}$ & $\begin{array}{c}\text { 12:00-13:00 } \\
\text { manual classes, reading } \\
\text { room }\end{array}$ \\
\hline $\begin{array}{l}13: 10-13: 40 \\
\text { classes in small groups or } \\
\text { individual, therapy of } \\
\text { cognitive functions using } \\
\text { paper - pencil boards, } \\
\text { Reha Com computer } \\
\text { program }\end{array}$ & $\begin{array}{c}13: 10-13: 40 \\
\text { classes in small groups or } \\
\text { individual, therapy of } \\
\text { cognitive functions using } \\
\text { paper - pencil boards, } \\
\text { Reha Com computer } \\
\text { program }\end{array}$ & $\begin{array}{c}13: 10-13: 40 \\
\text { classes in small groups or } \\
\text { individual, therapy of } \\
\text { cognitive functions using } \\
\text { paper - pencil boards, } \\
\text { Reha Com computer } \\
\text { program }\end{array}$ & $\begin{array}{c}\text { 13:10-13:40 } \\
\text { classes in small groups or } \\
\text { individual, therapy of } \\
\text { cognitive functions using } \\
\text { paper - pencil boards, } \\
\text { Reha Com computer } \\
\text { program }\end{array}$ & $\begin{array}{c}13: 10-13: 40 \\
\text { classes in small groups or } \\
\text { individual, therapy of } \\
\text { cognitive functions using } \\
\text { paper - pencil boards, } \\
\text { Reha Com computer } \\
\text { program }\end{array}$ \\
\hline
\end{tabular}




\begin{tabular}{ccccc}
\hline Monday & Tuesday & Wednesday & Thursday & Friday \\
\hline 13:40-14:00 & $13: 40-14: 00$ & $13: 40-14: 00$ & $13: 40-14: 00$ & $13: 40-14: 00$ \\
lunch-eating together & lunch-eating together & lunch-eating together & lunch-eating together & lunch-eating together \\
\hline $\begin{array}{c}\text { 14:00-15:00 } \\
\text { ergotherapy, together }\end{array}$ & $\begin{array}{c}\text { 14:00-15:00 } \\
\text { ergotherapy, together }\end{array}$ & $\begin{array}{c}\text { 14:00-15:00 } \\
\text { orgotherapy, together }\end{array}$ & $\begin{array}{c}\text { ergotherapy, together } \\
\text { ordering therapeutic rooms }\end{array}$ & $\begin{array}{c}\text { orgotherapy, together } \\
\text { ordering therapeutic rooms } \\
\text { ordering therapeutic rooms }\end{array}$ \\
\hline \hline
\end{tabular}


An evaluation of the cognitive and emotional functioning in the SB conducted at the study initiation (baseline), and after 6-month nonpharmacological actions conducted at the CD-CC.

A statistical analysis was conducted by using the Statistica 12.0 (Dell Software Information Management Group) program. In all of the tests, the $95 \%$ confidence level was used, and p<0,05 was considered as statistically significant.

Characteristics of the SG and CG are presented in Table 2.

Table 2. Characteristics of the study and control groups.

\begin{tabular}{|c|c|c|c|}
\hline Variable & $\begin{array}{c}\mathrm{SG} \\
\mathrm{n}=46\end{array}$ & $\begin{array}{c}C G \\
n=45\end{array}$ & p value* \\
\hline sex: women / men [\%] & $25 / 21$ & $33 / 12$ & NS \\
\hline age [years] & 66 [range: 56-85] & 69 [range 58-86] & NS \\
\hline $\begin{array}{l}\text { place of resident } \\
\text { town / village [\%] }\end{array}$ & 9 / 91 & $67 / 33$ & $p<0,00001$ \\
\hline $\begin{array}{l}\text { type of residence } \\
\text { single /with family [\%] }\end{array}$ & $50 / 50$ & $47 / 53$ & NS \\
\hline $\begin{array}{l}\text { assessment of material situation } \\
\text { good / medium / bad [\%] } \\
\text { Education }\end{array}$ & 17 / 74 / 9 & 35 / 59 / 6 & NS \\
\hline $\begin{array}{l}\text { higher / vocational / secondary / primary } \\
\qquad[\%]\end{array}$ & 0 / 25 / $11 / 64$ & 13 / 2742 / 18 & $\mathrm{p}=0,0000145$ \\
\hline $\begin{array}{c}\text { functional efficiency } \\
\text { independent / needs help [\%] } \\
\text { other mental disorders [\%]: }\end{array}$ & $94 / 6$ & $100 / 0$ & NS \\
\hline depression & 40 & \multirow{5}{*}{ did not declare } & \multirow{5}{*}{ - } \\
\hline anxiety disorders & 7 & & \\
\hline affective disorders & 6 & & \\
\hline mood and personality disorders & 17 & & \\
\hline dementia & 30 & & \\
\hline
\end{tabular}

* $\quad$ Chi-square test, $\mathrm{p}<0,05$

A comparison of the cognitive tests results between the SG and the CG, at baseline (before starting the study intervention for the SG) is presented in Table 3. 
Table 3. Cognitive tests results in groups before intervention.

\begin{tabular}{cccccc}
\hline \hline Test & M & SG & & CG & \\
& SD & M & SD & P \\
\hline \hline MMSE & 23,174 & 4,963 & 26,267 & 3,033 & 0,002 \\
CDT & 1,5 & 0,81 & 1,133 & 0,405 & 0,012 \\
L-VFT correctly & 10,594 & 2,608 & 11,778 & 3,269 & 0,105 \\
L-VFT errors & 1,789 & 1,408 & 1,037 & 1,427 & 0,003 \\
C-VFT correctly & 12,587 & 5,256 & 12,600 & 6,390 & 0,673 \\
C-VFT errors & 0,435 & 0,75 & 0,200 & 0,548 & 0,198 \\
DST F & 7,1080 & 1,816 & 7,178 & 2,863 & 0,445 \\
DST B & 4,304 & 9,138 & 4,156 & 2,374 & 0,023 \\
DST T & 9,886 & 3,366 & 11,267 & 4,779 & 0,047 \\
SCWT I time & 47,104 & 35,829 & 40,758 & 36,368 & 0,020 \\
SCWT II time & 50,867 & 41,217 & 48,444 & 45,639 & 0,044 \\
SCWT I errors & 0,261 & 0,743 & 0,111 & 0,611 & 0,387 \\
SCWT II errors & 1 & 2,459 & 1,444 & 3,671 & 0,45 \\
\hline \hline
\end{tabular}

*Test U Manna-Withneya; MMSE - Mini Mental State Examination ; CDT - Clock Drawing Test; VFT- Verbal Fluency Test; Letter -VFT; Category-VFT (Animals); DST- Digit Span Test; DST Forward; DST Backward; DST TOTAL; SCWT- Stroop Color and Word Test; SCWT part I; SCWT part II, M- arithmetic average, SD- standard deviations

The cognitive tests results in the CG remained within normal limits, while in SG, they were indicative of mild cognitive impairment. Considering, according to the literature, the cut-off value for MMSE below 24 points, it was found that in 24 participants (52\%) in the SG, clinical symptoms of dementia were present, while in the CG, dementia was present in only 9 participants (20\%).

Considering, according to the literature, the cut-off value for CDT above 1point, it was found that in 21 participants $(46 \%)$ in the SG, clinical symptoms of dementia were present, while in the CG, dementia was present in only 5 participants (11\%).

A comparison of the cognitive tests results in the SG between the baseline (before starting the study) and after 6-month therapy intervention is presented in Table 4. 
Table 4. Cognitive tests results in study group before and after intervention.

\begin{tabular}{|c|c|c|c|c|c|}
\hline \multirow{2}{*}{ Test } & \multicolumn{2}{|c|}{ before intevention } & \multicolumn{2}{|c|}{ after intervention } & \multirow{2}{*}{$\mathrm{p}^{*}$} \\
\hline & $\mathrm{M}$ & SD & $\mathrm{M}$ & SD & \\
\hline MMSE & 23,174 & 4,963 & 23,913 & 5,299 & 0,0675 \\
\hline CDT & 1,5 & 0,81 & 1,391 & 0,856 & 0,372 \\
\hline L-VFT correctly & 10,594 & 2,608 & 10,985 & 2,649 & 0,118 \\
\hline L-VFT errors & 1,789 & 1,408 & 1,079 & 1,180 & 0,001 \\
\hline C-VFT correctly & 12,587 & 5,256 & 12,717 & 6,742 & 0,941 \\
\hline C-VFT errors & 0,435 & 0,75 & 0,261 & 0,535 & 0,263 \\
\hline DST F & 7,1080 & 1,816 & 6,956 & 2,118 & 0,727 \\
\hline DST B & 4,304 & 9,138 & 2,652 & 1,864 & 0,457 \\
\hline DST T & 9,886 & 3,366 & 9,608 & 3,276 & 0,229 \\
\hline SCWT I time & 47,104 & 35,829 & 44,46 & 39,616 & 0,472 \\
\hline SCWT II time & 50,867 & 41,217 & 47,223 & 26,287 & 0,933 \\
\hline SCWT I errors & 0,261 & 0,743 & 0,087 & 0,285 & 0,123 \\
\hline SCWT II errors & 1 & 2,459 & 0,609 & 1 & 0,39 \\
\hline
\end{tabular}

* Wilcoxon pairs order test; MMSE - Mini Mental State Examination ; CDT - Clock Drawing Test; VFT- Verbal Fluency Test; Letter -VFT; Category-VFT (Animals); DST- Digit Span Test; DST Forward; DST Backward; DST TOTAL; SCWT- Stroop Color and Word Test; SCWT part I; SCWT part II

After the therapeutic nonpharmacological intervention conducted at the CD-CC, in the SG, the number of participants, in whom cognitive impairment at the level of dementia (based on the MMSE scores) had been found, was decreased from 24 (52\%) to 20 participants (43\%).

In the CG, mild cognitive impairment symptoms were reported in 9 participants (20\%).

Similarly, in the CDT, in the SG, the number of participants, with the scores indicative of dementive disorders, was decreased from 21 participants $(46 \%)$ before the therapy to 14 participants $(30 \%)$ after the therapy.

In the CG, based on the CDT, dementia symptoms was found in 5 participants (11\%).

A comparison of the cognitive tests results between in the SG and CG, after 6-month therapy intervention (in the SG) is presented in Table 5. 
Table 5. Cognitive tests results in study and control groups after intervention.

\begin{tabular}{cccccc}
\hline \hline Test & \multicolumn{2}{c}{ SG } & \multicolumn{2}{c}{ CG } & P \\
\hline MMSE & 23,913 & 5,299 & 26,267 & 3,033 & 0,103 \\
CDT & 1,391 & 0,856 & 1,133 & 0,405 & 0.405 \\
L-VFT corectly & 10,986 & 2,649 & 3,269 & 3,269 & 0,306 \\
L-VFT errors & 1,080 & 1,180 & 1,427 & 1,427 & 0,545 \\
C-VFT corectly & 12,717 & 6,742 & 6,390 & 6,390 & 0,915 \\
C-VFT errors & 0,261 & 0,535 & 0,548 & 0,548 & 0,610 \\
DST F & 6,957 & 2,118 & 2,863 & 2,863 & 0,284 \\
DST B & 2,652 & 1,864 & 2,374 & 2,374 & 0,003 \\
DST T & 9,609 & 3,276 & 4,779 & 4,779 & 0,019 \\
SCWT I time & 44,46 & 39,616 & 40,758 & 36,368 & 0,057 \\
SCWT II time & 47,223 & 26,287 & 48,444 & 45,639 & 0,034 \\
SCWT I errors & 0,087 & 0,285 & 0,111 & 0,611 & 0,743 \\
SCWT II errors & 0,609 & 1 & 1,444 & 3,671 & 0,499 \\
\hline \hline
\end{tabular}

* U Manna-Withney test;; MMSE - Mini Mental State Examination ; CDT - Clock Drawing Test; VFT- Verbal Fluency Test; Letter -VFT; Category-VFT (Animals); DST- Digit Span Test; DST Forward; DST Backward; DST TOTAL; SCWT- Stroop Color and Word Test; SCWT part I; SCWT part II

A comparison of the BDI and HADS tests results between the SG and the CG, at baseline (before the study intervention in the SG) is presented in Table 6.

Table 6. BDI and HADS results in both groups before intervention.

\begin{tabular}{cccccc}
\hline \hline \multirow{2}{*}{ Test } & SG & \multicolumn{3}{c}{ CG } & $\mathrm{p}^{*}$ \\
\hline \hline BDI & M & SD & M & SD & 0,014 \\
HADS D & 74,087 & 7,947 & 11,133 & 9,445 & 0,052 \\
HADS L & 5,217 & 3,7 & 5,867 & 3,823 & 0,0746 \\
\hline \hline
\end{tabular}

* U Manna-Withney test; BDI - Beck Depression Inventory; HADS - Hospital Anxiety and Depression Scale; HADS D - depression scale; HADS L - anxiety scale

Considering, according to the literature, the cut-off value for BDI > 10 points, it was found that in 29 participants $(63 \%)$ in the SG, clinical symptoms of depression were present, while in the CG, depression was present in 19 participants (42\%).

Upon applying for the HADS test, a universally accepted cut-off value $>7$ points, the clinical symptoms of depression were found in the SG, in 10 participants (21\%), and in the CG, in 8 participants $(17 \%)$.

Subsequently, symptoms of anxiety were present in 25 participants (54\%) in the SG, and in 14 participants $(31 \%)$ in the CG.

A comparison of the BDI and HADS tests results in the SG, between the baseline (before the study intervention) and after the study intervention is presented in Table 7. 
Table 7. BDI and HADS results in study group before and after intervention.

\begin{tabular}{cccccc}
\hline \multirow{2}{*}{ Test } & \multicolumn{2}{c}{ before intervention } & \multicolumn{2}{c}{ after intervention } & $\mathrm{p}^{*}$ \\
& $\mathrm{M}$ & SD & $\mathrm{M}$ & $\mathrm{SD}$ & 0,0000217 \\
\hline BDI & 13,392 & 7,993 & 8,882 & 7,016 & 0,00001 \\
HADS D & 7,02 & 3,744 & 4,02 & 3,717 & 0,000556 \\
HADS L & 5,216 & 3,997 & 3,196 & 3,188 & 0 \\
\hline \hline
\end{tabular}

* Wilcoxon pairs order test; BDI - Beck Depression Inventory; HADS - Hospital Anxiety and Depresion Scale; HADS D - depression scale; HADS L - anxiety scale

The mean scores in the SG before the study intervention were in the range of values fordepressive disorder, according to both the BDI and the HADS scales. In contrast, after the study intervention, the scores were within normal range.

A comparison of the BDI and HADS tests results between the SG (after the study intervention) and the CG is presented in Table 8.

In addition, after the study intervention, no evidence of depressive or anxiety disorders was found in the SG, and the symptoms of depression, based on the HADS scale, had significantly lower intensity than in the CG.

Table 8. BDI and HADS results in study and control groups after intervention.

\begin{tabular}{|c|c|c|c|c|c|}
\hline \multirow{2}{*}{ Test } & \multicolumn{2}{|c|}{ SG } & \multicolumn{2}{|c|}{ CG } & \multirow{2}{*}{$\mathrm{p}^{*}$} \\
\hline & $\mathrm{M}$ & SD & M & SD & \\
\hline BDI & 9,326 & 7,171 & 11,133 & 9,445 & 0,638 \\
\hline HADS D & 4,239 & 3,766 & 5,867 & 3,823 & 0,0244 \\
\hline HADS L & 3,065 & 3,094 & 3,978 & 3,876 & 0,349 \\
\hline
\end{tabular}

* U Manna-Withney test; BDI - Beck Depression Inventory; HADS - Hospital Anxiety and Depression Scale; HADS D - depression scale; HADS L - anxiety scale 


\section{Discussion}

\section{Cognitive functioning}

Elderly persons admitted to the community day-care center (CD-CC) type $C$ display significantly worse cognitive functioning level, compared to a general older population. In our study, we report that the participants from the SG scored worse in almost all of the tests evaluating cognitive performance (that were used in the study), compared to the participants from the CG. In fact, these results have been expected, because of the indications for admission to the $\mathrm{CD}-\mathrm{CC}$, which include cognitive dysfunctions and disorders, both primary and secondary, due to associated somatic and mental diseases.

It should be highlighted that all the applied tests have revealed a good sensitivity in the range of identification of cognitive function abnormalities among the elderly persons, and were able to distinguish between the SG and the CG. This confirms the usefulness of the applied measuring tools, in the study population, and indicates a selection of a short set of screening tests for evaluation of elderly persons admitted to the CD-CC (based on those, which were used in our study). The obtained results have also revealed a relatively general character of the identified disorders that can be possibly explained by frequently occurring depression (that was present in a large percentage in the SG) and attention disorders, which affect the performance level of all the remaining tests.

Simultaneously, it is interesting that despite obtaining statistically significant differences in the results from both groups, the absolute differences in these results were not very big. Therefore, we can presume that the properly adjusted intervention for elderly persons with chronic mental disorders (e.g., chronic disturbances of mental functioning of the organic origin, related to comorbidities associated with aging) may improve their functioning to some degree, so that, they can achieve a similar level of the functional status to their healthy older peers. Based on the literature review, the expected improvement of mental functions can be achieved not only with regard to an intervention in the form of cognitive training, but also physical activity. For instance, in their study, Ji et al. [9] have found that the physical exercises have improved the walking speed and the cognitive functions, involving some compensatory mechanisms (which activated both of these abilities, among the engaged patients) [9]. In our analysis of the effects of study intervention at the CD-CC, in the SG, we have reported the improvement of the tests scores compared to a baseline. In particular, in the SG, a statistically significant improvement after the 6-month intervention was obtained in the area of verbal fluency (measured by the VFT) that was manifested by a lower number of the committed errors.

In the case of the remaining tests, the differences were not statistically significant. In contrast, it should be highlighted that after the 6-month intervention at the CD-CC, the results obtained in the SG, in the majority of the examined areas were approximated to those from the CG. In contrast to the baseline scores, in the majority of tests, the differences between the SG and the CG (after the 6-month intervention in the SG) were not statistically significant. This observation allows to assume that the intervention conducted at the CD-CC has a positive impact on the cognitive functions in the elderly participants (with chronic disturbances of mental functioning of the organic origin, related to comorbidities associated with aging). In the context of the studies described in the literature, relevant to the cognitive impairment in older age groups (particularly those afflicted by additional diseases and features of pathologic aging), the results of our study that have revealed some cognitive improvement, after the intervention in the SG, seem to be optimistic.

\section{Anxiety and Depression}

Progress in medicine, pharmacology, and improvement of living conditions in the contemporary world cause that people live longer, but their mental health deteriorates, due to coexisting somatic disorders, loss of independence and autonomy, feelings of being misunderstood, experience of injustice, lack of influence on the surroundings, loss of purpose in life, pessimism, and 
fear of new or unknown events and changes that in consequence can cause deteriorated mood and depression [10].

In our study, elderly persons admitted to $C D-C C$ type $C$ had significantly worse results compared to the $\mathrm{CG}$, in the area of depression and anxiety symptoms measured by the BDI and HADS scales. The fact that the depressive symptoms were found in as much as $63 \%$ of persons qualified for the therapy at CD-CC type $C$ is not surprising, since this facility has a profile of the therapeutic center for persons with so-called other disorders of mental functions, such as depression. In contrast, $45 \%$ of persons with depressive features among the attendees of the U3A, confirms a very high prevalence of depression among elderly persons, even the active ones. The results of examination of depression in this population indicate that $10 \%$ of patient population of the family physicians suffer from depression [11]. In our study, the percent of depression in older adults was 4,5 times higher. A possible cause of this phenomenon may be related to insufficient diagnosing of the family physicians' patient population. Therefore, it is currently indicated to perform depression screening test in each elderly person.

In addition, in the SG, the anxiety symptoms were more prevalent - in 25 participants (54\%), compared to 14 participants (31\%) in the CG (based on the HADS scores). With the use of the HADS tool, the presence of clinical symptoms of depression was found in the SG in 10 participants $(21 \%)$, compared to 8 participants $(17 \%)$ in the CG. It should be noted that in the case of both of these measuring tools, the results are coherent and indicate a higher prevalence of depression in the SG, compared to the CG. In contrast, the different absolute values may be relevant to the various sensitivity of these scales in elderly adults attending CD-CC. However, at this point, the BDI appears to a more accurate diagnostic tool.

It should be underscored that the intervention conducted at the CD-CC had a positive influence on the reduction of these symptoms among the study participants, who have revealed on both scales statistically significant improvements. Both BDI and HADS have shown sensitivity in the area of assessment of the mental functioning improvement, in the older participants undergoing the therapeutic intervention.

In an analysis of the SB scores, after the study intervention, it can be noted that according to the BDI scale and the anxiety HADS-A subscale, the proposed nonpharmacological intervention allowed to approximate the mental functioning level in the SG and CG. An evaluation of the effects of nonpharmacological interventions (similar to the one that was implemented at the $\mathrm{CD}-\mathrm{CC}$ ) on the mental health status of elderly persons represents an important field of investigations for many researchers worldwide [12,13].

A review of research on the impact of physical activity on mental and somatic status of the elderly adults has indicated that the physical activity can be an alternative to pharmacological therapy for the depressive disorders, and thus, it can affect the reduction of costs related to medical care for the older persons $[14,15]$. Furthermore, regular physical exercises, physical therapy, and respiratory exercises cause the reduction of depressive symptoms, mental disorders, and anxiety states. Moreover, the improvement occurs also in the area of social functioning, somatic conditions, physical performance, as well as cognitive functions, attention span, and memory.

Interesting results were reported in the group of people over 60 years of age, who participated in a combined program of exercise and laughter therapy in Japan [16]. This intervention has revealed benefits in both physical and mental health areas. In this study, it was found that the positive emotions and laughter may contribute to the increase of motivation of elderly persons to the participation in exercises, and also can exert beneficial effects on the increase of glucose metabolism during physical activities [16]. Similarly, in our study, the therapeutic interventions applied in the CD$\mathrm{CC}$, were also a source of positive emotions for the participants, and in consequence, they have been considered to be a factor of the mental status improvement.

In our study analysis of the therapeutic intervention conducted at the CD-CC, it should be pointed out that the dance therapy represents a preferred form of activity among the study participants. Eyigor et al. [17] have shown that dance therapy has a positive impact on physical 
performance, balance, and depressive symptoms level, as well as the reduction of costs relevant to medical care for the elderly persons [17]. In this study, it has been revealed that only after 6 weeks of dance therapy, an intensity of the depressive symptoms was decreased and physical performance of the older participants was increased. In particular, in the participants of this study, self-esteem, personality development, vitality sense, and inner equilibrium, as well as an ability to "reconnect" with bodily sensations and the quality of life were improved [17].

Moreover, many researchers believe that cognitive performance is related to the severity level of depression and in a consequence, together with the decrease of depressive symptoms, cognitive functions can often be improved $[18,19]$. Such a relation has also been reported in our study, where these changes were parallel.

In the context of the improvement of emotional functioning in the SG, it can be assumed that the therapeutic interventions provided in the CD-CC have positive influence on cognitive functions and mood in elderly persons attending such programs. Furthermore, these interventions may lead to the reduction of anxiety and depressive symptoms.

\section{Strengths and Limitations}

The topic of community day-care centers has rarely been studied in research. In this study, for the first time, we have tried to determine, in the standard fashion, the objective changes that occur in elderly persons using the therapeutic services in the CD-CC type C.

Another advantage includes the application in this study a different from the previously used perspective of looking at the major tasks of CD-CC, transferring the traditional accent from a generally understood social integration, to which the applied therapy, focused on concrete cognitive functions and aspects of emotional functioning (which may consist both the separate value and basis of improvement of the social integration).

The main limitations of our study include its pilot character and small sample size. Of course, upon conducting another observation in this area, the group size should be increased. In addition, the recruited study participants should be stratified, and categorized to different groups, depending on their main diagnostic findings (in order to increase homogeneity within the groups). Moreover, it would be beneficial to implement a battery of neuropsychological tests that would reflect a slightly wider cognitive and emotional profile. Simultaneously, such assessments would consider both the larger impact of clinical and demographic parameters and the influence of the concrete type of provided intervention (e.g., a specific type of occupational therapy) on the occurring changes (that are being examined).

In the future research projects it would also be important to consider an objective follow-up assessment that could facilitate evaluation of long-term effects of the specific therapy, both in persons who continue and terminate the utilization of supportive services at the CD-CC.

\section{Conclusions}

The nonpharmacological complex therapy rendered at the CD-CC can be helpful for the older adult population, in terms of the benefits in cognitive and emotional functioning. However, prospective studies on large populations are merited to further elucidate this topic. 


\section{REFERENCES:}

1. Li, M.; Zhong, R.; Zhu, S.; Ramsay, L.C.; Li, F.; Coyte, P.C. Access to Community Living Infrastructure and Its Impact on the Establishment of Community-Based Day Care Centres for Seniors in Rural China. Int J Environ Res Public Health 2018, 15, 1184.

2. Tuckett, A.G.; Freeman, A.; Hetherington, S.; Gardiner, P.A.; King, A.C. On behalf of Burnie Brae Citizen Scientists. Older adults using our voice Citizen Science to Create Change in their neighborhood environment. Int J Environ Res Public Health 2018, 15, 2685.

3. Depression and Other Common Mental Disorders: Global Health Estimates. Geneva: World Health Organization; 2017. Licence: CC BY-NC-SA 3.0 IGO.

4. Sozeri-Varma, G. Depression in the elderly: clinical features and risk factors._Aging Dis. 2012, 3(6), 465471.

5. Bredesen, D.E.; Amos, E.C.; Canick, J.; Ackerley, M.; Raji, C.; Fiala, M.; Ahdidan, J. Reversal of cognitive decline in Alzheimer's disease. Aging 2016, 8, 1250-1258.

6. Cremers, G.; Taylor, E.; Hodge, L.; Quigley, A. Effectiveness and acceptability of low-intensity psychological interventions on the well-being of older adults: A systematic review. Clin Gerontol 2019, $11,1-21$.

7. Wilberforce, M.; Batten, E.; Challis, D.; Davies, L.; Kelly, M.P.; Roberts, C. The patient experience in community mental health services for older people: A concept mapping approach to support the development of a new quality measure. BMC Health Services Research 2018, 18 (1), 461.

8. Rubinstein, L.Z.; Rubinstein, L.V. Multidimensional geriatric assessment. In Brocklehurst's Textbook of Geriatric Medicine and Gerontology, 8th ed.; Fillit, H.; Rockwood, K.; Young J.B.; Elsevier Science Limited, 2016.

9. Ji, L.; Pearlson, G.D.; Zhang, X.; Steffens, D.C.; Ji, X.; Guo, H.; Wang, L. Physical exercise increases involvement of motor networks as a compensatory mechanism during a cognitively challenging task. Int J Geriatr Psychiatry 2018, 33(8), 1153-1159.

10. Martin, P.; Kelly, N.; Kahana, B.; Kahana, E.; Willcox, B.J.; Willcox, D.C.; Poon, L.W. Defining successful aging: a tangible or elusive concept? Gerontologist 2015, 55(1), 14-25.

11. Park, M.; Unützer, J. Geriatric depression in primary care. Psychiatr Clin North Am 2011, 34, 469-487.

12. Blair, A.C.; Bird, M.J. A pilot trial of psychological therapy groups for the very old in residential care: Clinical and logistical issues. Clinical Psychologist 2016, 20(2), 68-79.

13. Chan, P.; Bhar, S.; Davison, T.E. (2018) Characteristics of cognitive behavioral therapy for older adults living in residential care: Protocol for a systematic review. J Med Internet Res 2018, 20(7), e164.

14. Morga, P.; Traczyk, J.; Wittenbeck, K.; Zygmont, A. Review of research on the impact of physical activity on mental state of the elderly. Fizjoterapia 2015, 23 (2), 42-51.

15. Giné-Garriga, M.; Sandlund, M.; Dall, P.M.; Chastin, S.F.M.; Pérez, S.; Skelton, D.A. A Novel Approach to Reduce Sedentary Behaviour in Care Home Residents: The GET READY Study Utilising ServiceLearning and Co-Creation. Int J Environ Res Public Health 2019, 16, 418.

16. Hirosaki, M.; Ohira, T.; Kajiura, M.; Kiyama, M.; Kitamura, A.; Sato, S.; Iso, H. The impact of a programme of exercise and laughter therapy on physical and mental health on elderly persons living in Japan; studying programme effects. Geriatr Gerontol Int 2013, 13(1), 152-160.

17. Eyigor S.; Karapolat H.; Durmaz B.; Ibisoglu U.; Cakir S. Determining whether a Turkish folk dance has an impact on physical performance, balance, depression and quality of life in elderly women. Arch Gerontol Geriatr 2009, 48(1), 84-8.

18. Perini, G.; Ramusino, M.C.; Sinforiani, E., Bernini, S.; Petrachi, R.; Costa A. Cognitive impairment in depression: recent advances and novel treatments. Neuropsychiatr Dis Treat. 2019, 15, 1249-1258.

19. Slam, R.W.; Kennedy, S.H.; McIntyre, R.S.; Khullar. A. Cognitive dysfunction in major depressive disorder: effects on psychosocial functioning and implications for treatment. Can J Psychiatry 2014, 59(12), 649-654. 